\title{
64-Kültürü çevirmek: Ayșe Kulin’in Veda: Esir Şehirde Bir Konak romanının Fairwell: A Mansion in Occupied İstanbul başlıklı çevirisi
}

Betül ÖZCAN DOST

\section{Elif GÜVENDİ YALÇIN²}

\begin{abstract}
APA: Özcan Dost, B.; Güvendi Yalçın E. (2020). Kültürü çevirmek: Ayşe Kulin'in Veda: Esir Şehirde Bir Konak romanının Fairwell: A Mansion in Occupied Istanbul başlıklı çevirisi. RumeliDE Dil ve Edebiyat Araşttrmalar Dergisi, (21), 1017-1030. DOI: 10.29000/rumelide.843739.
\end{abstract}

\section{$\ddot{O} \mathbf{z}$}

Kültürle ilgili incelemeler disiplinlerarası çalışmaya uygun bir doğaya sahip çeviribilimde önemli bir yer tutmaktadır. Kültürel öğelerin çevirisi üzerine yapılan çalışmalar çevirinin çok yönlü doğasını ortaya koymakta, kültürle ilgili farkındalı̆̆ı arttırmakta ve çevirmenin omuzlarındaki yükü görmemize yardımcı olmaktadır. Bu çalışmanın amacı, Ayşe Kulin’in Veda adlı eserinin Kenneth J. Dakan tarafından Farewell: A Mansion in Occupied Istanbul adıyla İngilizceye yapılan çevirisinde kaynak metinde sıklıkla yer alan kültürel öğelerin çevirisinde kullanılan çeviri stratejilerini ortaya koymaktır. Kültürel öğeler Peter Newmark’ın sınıflandırmasına göre Çevresel Unsurlar, Maddi Kültür, Sosyal Kültür, Kuruluşlar/gelenekler/faaliyetler/süreçler/kavramlar, Jestler ve alışkanlıklar şeklinde sınıflandırılmış, bu sınıflandırmaya Atasözü ve Deyimler eklenmiştir. Örnekler her madde için üçer tane (Sanatsal başlığı hariç) ve söz konusu maddeyi en net ve açılayıcı şekilde temsil edilmesi göz önünde bulundurularak seçilmiştir. Sınıflandırılan kültürel öğeler Sözcüğü Sözcüğüne Çeviri, Kültürel Öğenin Anlamını Çevirme, Kültürel Öğeyi Olduğu Gibi Bırakarak Yanına Açıklama veya Dipnot Ekleyerek Çevirme, Kültürel Öğeyi Çevirmeden Anlamını veya İşlevini Açıklayarak Çevirme, Serbest Çeviri ve Silme çeviri stratejileri bağlamında incelenmiştir. Yapılan karşılaştırmalı incelemenin sonucunda, çevirmenin tek bir çeviri stratejisi kullanmadığı, farklı stratejileri kullanarak çeviri sürecini yönettiği ve iki kültür arasındaki farklılıklardan kaynaklanan zorlukları bu şekilde aştığı görülmüştür. Ayrıca, çalışmanın başında belirlenen stratejiler dışında kültürel öğeyi olduğu gibi bırakma stratejisini de kullandı̆̆ı saptamıştır. Söz konusu çeviride en sık 1. stratejiye başvurulduğu, 2.2. ve 5.2. stratejiden ise en az sayıda faydalanıldı̆̆ı tespit edilmiş; 3.1. stratejiden hiç faydalanılmadı̆̆ı ve çalışmanın başında belirlenen stratejiler dışında "çevirmeden bırakma” yolunun da tercih edildiği görülmüştür.

Anahtar kelimeler: Çeviri stratejisi, edebi çeviri, kültürel öğeler, Newmark

\section{Translating culture: Translation of Ayşe Kulin's novel Veda: Esir Şehirde Bir Konak as Fairwell: A Mansion in Occupied İstanbul}

\author{
Abstract \\ Cultural studies play an important role in translation studies, which has a nature suitable for \\ interdisciplinary studies. Studies on the translation of cultural elements show the multifaceted \\ Dr. Öğr. Üyesi, 19 Mayıs Üniversitesi, Yabancı Diller Yüksekokulu, Mütercim Tercümanlı (İngilizce) Bölümü (Samsun, \\ Türkiye), betul.ozcan@omu.edu.tr, oooo-ooo3-3110-8017. [Araştırma makalesi, Makale kayıt tarihi: 19.11.2020-kabul \\ tarihi: 17.12.2020; DOI: 10.29000/rumelide.843739] \\ 2 Dr. Öğr. Üyesi, Gümüşhane Üniversitesi, Edebiyat Fakültesi, İngiliz Dili ve Edebiyatı Bölümü (Gümüşhane, Türkiye), \\ guvendielif@gmail.com, ORCID ID: 0ooo-0o01-7780-1613 \\ Adres


nature of translation, increase awareness about culture and help us see the burden on translators. The aim of this study is to reveal the translation strategies used in the translation of cultural elements in Ayşe Kulin's novel Veda as Farewell: A Mansion in Occupied Istanbul by Kenneth J. Dakan from Turkish into English. Cultural elements in the study are categorized as Ecology; Material Culture; Social Culture; Organizations, Customs, Ideas, Procedures, and Concepts; Gestures and Habits in accordance with Peter Newmark's categorization of cultural elements. The category of Proverbs and Idioms were also added to the categorization. Three example sentences (except the heading Art) were chosen for each category. These examples were chosen as they represent their categories in the most clear and explanatory way. The translation of the chosen cultural elements were analysed within the framework of the following translation strategies: Literal translation; Translation of Meaning; Use of Cultural Element itself by Adding Explanation or Footnotes; Translation of the Meaning or Function without Translating the Cultural Element itself; Free Translation and Deletion. As a result of the descriptive and comparative analysis, it was found out that the translator did not use one single translation strategy. Instead, he used different translation studies during the translation process and this way overcame the difficulties risen due to cultural elements. Furthermore, the translator also used the strategy of not translating the cultural element, which was not put forth in the beginning of the study. It was also seen that the strategy 3.2 was the most common and the strategies 2.2. and 5.2. were the least common. It was also revealed that the translator did not benefit from the strategy 3.1 at all and sometimes preferred "no translation", which was not one of the determined strategies in the beginning of the study.

Keywords: Translation strategy, literary translation, cultural elements, Newmark

\section{Giriş}

Çeviri eylemi dilsel ve kültürel yönüyle çok boyutlu ve çok katmanlıdır. 20. Yüzyıla kadar dilbilim ve dil öğretimi gibi farklı disiplinler altında incelenen çeviri eylemi bu tarihlerden itibaren bağımsız, ancak diğer disiplinlerle ilişki içinde olan bir bilim dalı olarak ele alınmaya başlamıştır.

Çeviri, en az iki dil ve iki kültürü içermesi sebebiyle doğası gereği karmaşık bir eylemdir. Diğer yandan, bu karmaşık doğasının alana zenginlik getirdiğini söylemek de yanlış olmayacaktır. Bu sebeple, çeviri eylemi ile ilgili olarak birçok kuramcı farklı fikirler ortaya atmıştır. Bu fikirler çevrilebilirlik, çeviri stratejileri, çeviri eleştirisi gibi alanları kapsamaktadır. Ortaya atılan bu fikirler çeviribilimciler, çeviri eleştirmenleri, çevirmenler, çeviri yapmayı öğrenenler ve öğretenler için yol gösterici olmaktadır.

Cicero'ya kadar dayanan kaynak metne sadık çeviri mi yoksa serbest çeviri mi tartışmasından sonra çeviri üzerine tartışmalar ve araştırmalar zamanla birçok aşamadan geçmiştir. Metin türlerine göre çeviri anlayışı üzerinde durulmuş, çevirinin değişik işlevleri göz önünde bulundurulmuş, çeviri bir iletişim aracı olarak ele alınmış ve çeviride anlam ve yapı eşdeğerlikleri araştırma konusu edilmiştir. Bu bağlamda, çeviri eyleminde göz önünde bulundurulması gereken bir diğer nokta çevirisi yapılacak metnin türüdür. Kaynak metnin türüne göre kullanılacak çeviri stratejileri değişiklik göstermektedir. Katherina Reiss metin türlerini Karl Bühler’in ayırdığı 3 dilsel işlev üzerinden gruplandırmıştır. Reiss, Bühler'deki betimleyici işlevin "içerik ağırlıklı", anlatım işlevinin "biçim ağırlıklı", seslenme işlevinin ise "çağrı ağırlıklı" metinleri oluşturduğunu belirtmektedir. Bu üç metin türüne ek olarak "işitsel araçlı” olarak adlandırdığı, radyo-televizyon oyunları, şarkı, opera sözü gibi metinleri kapsayan dördüncü bir metin türünden söz etmektedir. Daha sonra yaptığı bir çalışmasında bu metin türlerini daha açıklayıcı hale getirmek için yeniden adlandırarak "bilgilendirici" ve "anlatımcı" terimlerini

Adres

İstanbul Medeniyet Üniversitesi, Eğitim Bilimleri Fakültesi, Türkçe ve Sosyal Bilimler Eğitimi Bölümü, Türkçe Eğitimi ABD Cevizli Kampüsü, Kartal-İstanbul/TÜRKIYY e-posta: editor@rumelide.com
Address

İstanbul Medeniyet University, Faculty of Education Sciences,

Turkish and Social Scinces Education, Turkish Language Teaching

Education, Cevizli Campus, Kartal-İstanbul /TURKEY

e-mail: editor@rumelide.com 
kullanmıştır. Sonrasında ise dördüncü metin türünün adını "çok araçlı" olarak değiştirmiştir. Peter Newmark da çevirmenin bu dilsel işlevlerin herhangi birine göre ayarlanabilen bir dürbünle çalıştığını, kaynak metinde hangi işlev ağır basıyorsa çeviri yönteminin de ona göre seçildiğini belirtmektedir (Göktürk, 2004: 28).

Bu çalışmanın kapsamını da oluşturan edebi metinler (şiir, roman, oyun, öykü) anlatımcı metin türü altında ele alınmaktadır. Edebi metinler yazarının özgün dil kullanımlarını yansıtır. Bu sebeple, bu tür metinlerin çevirisinde kaynak metin yazarının sanatsal biçemini yönlendiren ilkeler de göz önünde bulundurulmalıdır. Burada amaç kaynak metin okurunda yaratılan etkinin erek metin okurunda da yaratılmasıdır. Bu tür metinlerde nesnel bilginin aktarılmasından çok, ses, sözcük, tümce ve bütün düzenindeki dilsel biçim özelliklerinin yansıtılması önem kazanmaktadır (Göktürk, 2004: 27). Diğer yandan, Ayşe Ece'nin de söz ettiği gibi, edebi eserler dil olmayan dünyayı ve insan ruhunu dil ortamına aktarır. Bu sebeple, henüz kendi dillerinden başka bir dile çevrilmeden önce- bir çeviri işlemini gerçekleştirmiş olurlar (Ece, 2016: 21). Bu bağlamda düşündüğümüzde, çeviri aslından çevirinin çevirisidir.

Figen Öztemel-Akbay ve Bilge Metin-Tekin'in de söz ettiği gibi, edebi çeviri, "diğer çeviri türleri arasında yoruma en fazla açı olan, estetik kaygısını en yoğun taşıyan, kültür etkisinin en çok görüldüğü ve dolayısıyla çevirmen için en uğraştırıcı türdür denebilir" (Öztemel-Akbay ve MetinTekin, 2018). Görüldüğü gibi, edebi metinlerin çevirisinde göz önünde bulundurulması gereken önemli unsurlardan biri de kültürel öğelerdir. Burada da önemli olan kaynak metin okurunda yaratılan etkinin kaynak metnin kültürünü bilmeyen ya da bu kültür hakkında az bilgiye sahip olan erek okur üzerinde de yaratılmasıdır.

Her metin türünde olduğu gibi, edebi metin çevirmenlerinin de karşlaşacakları birtakım zorluklar vardır. Bu zorlukların bazıları çeviri eyleminin genel zorluğundan gelmekle birlikte, bazıları metin türüne özgüdür. Öncelikle, çevirmenin bir metni okuma şekli sıradan bir okurunkinden farklıdır. Çevirmen, çözümleyici ve eleştirel bir okuma yapar. Metni doğru yorumlayabilmek için sürekli sorar ve kaynak metni erek metne en iyi şekilde aktarabilmenin endişesini taşır (Ece, 2016: 56).

Çevirmenin kaynak metni yeniden yazan bir yazar gibi titizlikle çalışması gerektiği de açıktır. Bu sebeple, edebi eser çevirmenlerinin "edebiyat (edebiyat kuramı, edebiyat tarihi ve edebiyat eleştirisi gibi konularda) ve kültür konusunda derin bir bilgiye sahip olmasının yanı sıra her iki dile iyi hâkim olmasını gerektirmektedir" (Köksal, 2008: 71). Nasıl ki kalp ameliyatı yapan bir cerrah vücudun geri kalanının göz ardı edemezse, çevirmen de metni onu çevreleyen kültürden bağımsız olarak ele alamaz (Bassnett-McGuire'da alıntılanmıştır, 1980:13).

Tüm bu düşünceler ışığında, bu çalışmanın ana amacı Ayşe Kulin’in Veda adlı eserinin Kenneth J. Dakan tarafından Farewell: A Mansion in Occupied Istanbul adiyla yapılan çevirisinde kaynak metinde sıklıkla rastlanan kültürel öğelerin çevirisinde kullanılan çeviri stratejilerini açıklamaktır. Yazarın bu çalışma kapsamında ele alınan eseri Veda: Esir Şehirde Bir Konak 2007 yllında Everest Yayınları tarafından yayımlanmıştır. Roman Osmanlı İmparatorluğu'nun son günlerine tanıklık etmektedir. Yazar dönemin gerçeklerinden yola çıkarak romanın kurgusunu oluşturmuştur. Romanda İmparatorluğun çöküş döneminde işgal altında bulunan İstanbul'da bir konakta yaşayan Maliye Nazırı Ahmet Reşat Bey ve ailesi anlatılmaktadır. Ahmet Reşat Bey ve ailesi aracılığıyla hem dönemin toplumsal yapısı, insanları ve insanların psikolojisi hem de Osmanlı aydını resmedilmektedir.

Adres ve Sosyal Bilimler Eğitimi Bölümü, Türkçe Eğitimi ABD Cevizli Kampüsü, Kartal-İstanbul/TÜRKIYYE e-posta: editor@rumelide.com 
İngilizceye çevirisi ise Kenneth J. Dakan tarafindan Farewell: A Mansion in Occupied Istanbul adiyla yapılmış ve Dalkey Archive Press tarafından yayımlanmıştır. Dakan bu çevirisinden sonra yazarın Sevdalinka adlı eserini 2013 yllında Sarajevo of Love and War adiyla ve 2014 yllında Rose of Sarajevo adıyla çevirmiştir. Bunun dışında Buket Uzuner (Istanbulians ve I am Istanbul) ve Perihan Mağden (Whom were we running from?) gibi farklı Türk yazarlarının kitaplarını da İngilizceye çevirmiştir. (http://www.worldcat.org/identities/lccn-no2008162483/)

Yazarın bu eserinin, yayınlandı̆̆ ülkelerde Osmanlı İmparatorluğu'nun bilinmeyen yönlerini ortaya koyması, Türk kültürüne ait gelenek ve görenekler, yemek ve kıyafetler gibi birçok öğe hakkında bilgi vermesi, bir Türk ailesinin 1. Dünya Savaşı sonrası yaşadıklarından yola çıarak dönemin Osmanlı İmparatorluğu'nun siyasi ve toplumsal yapısını yansıtması oldukça önemlidir. Bunu yaparken de doğrudan bilgilendirici bir şekilde değil, yarı kurgusal bir ağ içerisinde anlatması daha geniş kitlelere ulaşmasını sağlamıştır. Bu şekilde hem Türk kültürünün hem Türk edebiyatının yurtdışında tanıtılmasına katkıda bulunmuştur.

\section{Yöntem}

Kültürel öğelere yoğun olarak yer verilen metinlerin çevirilerinin incelenmesi hem çevirmenlerin bu öğeleri çevirmek için kullandığı stratejilerin ortaya konması, hem de çevirmenler ve çevirmen adaylarına fikir vermesi açısından oldukça önem taşımaktadır. Kültürler arası aracı konumunda olan çevirmenin ortaya koyduğu çeviri ürününde kaynak metnin iletisinin erek kültürde "başarıll" sayılabilmesi ve işlevini yerine getirebilmesi, kaynak okurda yarattığı etkiyi erek okurda da yaratması büyük oranda çevirmenin sorumluluğunda görülmektedir. Bir diğer deyişle, çeviri aracıllğıyla kültürlerarası aktarımı sağlama sorumluluğu çevirmene verilmiştir.

Kültürün çevirideki önemini gören birçok kuramcı ise bu konu ile ilgili fikir yürütmüş, kuramlar ve tanımlar ortaya koymuştur. Örneğin, Hans Vermeer, Göhring’in Goodenough'tan uyarladığı kültür tanımını benimsemekte, kültürü "bir insan topluluğunun, yani toplumun potansiyel davranış biçimleri” olarak tanımlamakta ve çevirinin sadece dilsel bir aktarım değil, aynı zamanda kültürel bir aktarım olduğunu belirtmektedir (Dizdar, 2004). Eugene A. Nida ise kültürü "bir toplumun inançları ve uygulamaları toplamı” olarak tanımlamaktadır (Nida, 1993: 79). Öte yandan, David Katan kültürü dünyanın paylaşlan bir modeli olarak görmekte, bu modeli insanların hareketlerini ve etkileşimlerini yönlendirebilen inançlar, değerler ve stratejilerin bir hiyerarşik modeli olarak açıklamaktadır (Katan, 2009: 70).

Bu çalışma kapsamında ise Newmark'ın kültürü ve çeviri ve kültür arasındaki ilişkiyi ele alış biçimi temel alınmıştır. Newmark kültürü "İfade aracı olarak belirli bir dili kullanan bir topluma özgü yaşam biçimi ve onun dışavurumu” olarak tanımlamaktadır. Ayrıca, kültürün odak noktası olduğu durumlarda kaynak ve erek metin arasındaki "kültürel boşluk" veya "mesafe"den kaynaklanan çeviri sorunu ortaya çıkacağını savunmaktadır. Bunların yanında, kültürel öğelerin çevirilerinde kaynak metinde var olan bütün kültürel kazanımların farkında olunması ve bütün yabancı ülke ve kültürlere saygı duyulması gerektiğini vurgulamaktadır (Newmark, 1988: 96). Bu düşüncelerden yola çıkarak, Newmark, Nida'dan yola çıkarak kültürel öğeleri 5 temel kategoriye ayırmaktadır:

\footnotetext{
Adres $\mid$ Address

İstanbul Medeniyet Üniversitesi, Eğitim Bilimleri Fakültesi, Türkçe İstanbul Medeniyet University, Faculty of Education Sciences, ve Sosyal Bilimler Eğitimi Bölümü, Türkce Eğitimi ABD Cevizli Turkish and Social Scinces Education, Turkish Language Teaching Kampüsü, Kartal-İstanbul/TÜRKIYY $\quad$ Education, Cevizli Campus, Kartal-İstanbul /TURKEY e-posta: editor@rumelide.com 1 e-mail: editor@rumelide.com
} 


\section{1. Çevresel unsurlar (hayvan ve bitki varlığı, rüzgârlar, platolar, tepeler, buz, vb.)}

Newmark’a göre coğrafi özelliklerin diğer kültürel öğelerden farkı genellikle siyasi ve ticari değer yargılarından bağımsız olmalarıdır ve bu terimlerin yaygınlıkları ait oldukları ülkenin önemine ve spesifiklik derecelerine bağlıdır.

\section{Maddi kültür}

a. Yiyecek

b.

c. Ev ve kasaba

d. Ulaşım

\section{Sosyal kültür}

a. İş

b. Boş zaman etkinlikleri

Newmark sosyal kültür öğelerinin çevirilerinde düz anlamsal ve yan anlamsal çeviri sorunlarının ayırt edilmesi gerektiğini belirtir.

\section{Kuruluşlar, gelenekler, faaliyetler, süreçler, kavramlar}

a. Siyasi ve idari

b. Dini

c. Sanatsal

\section{Jestler ve alışkanlıklar}

Newmark jestlerin farklı kültürlerde tanımlarının ve işlevlerinin farklı olabileceği durumlar bulunduğunu söyler. Bir jestin başka bir kültürde var olmayabileceğini ya da farklı bir anlamı olabileceğini belirtir (Newmark, 1988: 95).

Yukarıda verilen sınıflandırmaya ek olarak, kültürün ayrılmaz bir parçası olan atasözleri ve deyimlere de bu çalışmada yer verilmiştir. Bu çalışma bağlamında atasözleri "Uzun deneme ve gözlemlere dayanılarak söylenmiş ve halka mal olmuş, öğüt verici nitelikte sözler” olarak; deyimler ise "Genellikle gerçek anlamından az çok ayrı, kendine özgü bir anlam taşıyan kalıplaşmış söz öbekleri, tabirler" olarak ele alınmıştır (www.tdk.gov.tr).

Bu çalışma kapsamında Ayşe Kulin'in Veda: Esir Şehirde Bir Konak adlı eserinin tamamı (387 sayfa) incelenmiş̧ir. Romanın kültürel öğelerin oldukça yoğun olduğu bir eser olması sebebiyle eserde tespit edilen her kategori için kitap içinde sıklıkla geçen üçer tane cümledeki temsili örneğe yer verilmiştir. Sadece Sanatsal başlığı altında iki örneğe yer verilmiştir. Sanatsal başlığı altında ele alınabilecek diğer

\footnotetext{
\begin{tabular}{r|l} 
Adres & Address \\
İstanbul Medeniyet Üniversitesi, Eğitim Bilimleri Fakültesi, Türkçe & İstanbul Medeniyet University, Faculty of Education Sciences,
\end{tabular} ve Sosyal Bilimler Eğitimi Bölümü, Türkce Eğitimi ABD Cevizli $\quad$ Turkish and Social Scinces Education, Turkish Language Teaching Kampüsü, Kartal-İstanbul/TÜRKIYY $\quad$ Education, Cevizli Campus, Kartal-İstanbul /TURKEY e-posta: editor@rumelide.com 1 e-mail: editor@rumelide.com
} 
kültürel öğelerin aynı zamanda Boş Zaman Etkinlikleri başlığıyla örtüşmesi sebebiyle tekrardan kaçınmak amacıyla bu yol tercih edilmiştir. Dolayısıyla, bu çalışma söz konusu kitabın çevirisinde ağırlıklı olarak yer verilen çeviri stratejilerini ortaya koyma amacı taşımamaktadır. Çevirmenlerin bu tür metinlerin çevirisinde kullandığı çeşitli stratejileri ortaya koymayı ve bu anlamda fikir vermeyi hedeflenmektedir. Çalışma kapsamında ilk önce kaynak metindeki kültürel öğeler belirlenmiş, daha sonra bu öğelerin İngilizceye nasıl çevrildikleri karşılaştırmalı inceleme yapılarak tespit edilmiştir. Aynı cümlede, verilen başlığa uygun birden fazla kültürel öğe olması durumunda tüm kültürel öğelere yer verilmiştir.

Bu çalışmada çeviri stratejisi "Çevirmenlerin bir metni seçerken ve çevirirken o metne yaklaşımları ve aktarım sırasında benimsedikleri birtakım yöntemler" olarak ele alınmıştır (Gürçăglar, 2011: 38). Suna Ağıldere ve Şirin Okyayuz Yener'in The Problem of the Translation of Cultural Features in Yaşar Kemal's Novel Ortadirek as the Wind from the Plain into English and as Le Pilier into French adl eserlerinde saptanan çeviri stratejilerinden yararlanılmıştır:

\section{1) Sözcüğü sözcüğüne çeviri}

Çeviri metinde "çeviri kokma" ihtimali göze alınarak kaynak metne bağlı bire bir çeviri yapma stratejisidir.

\section{2) Kültürel öğenin anlamını çevirme}

2.1) Anlamı açıklayarak çevirme: Kültürel ifadelerin anlamını çevirip ek bilgi sağlayarak çeviri yapma stratejisidir.

2.2) Bir sözcüğü iki sözcükle ifade ederek çevirme: Kaynak metinde bir sözcükle ifade edilen kültürel öğenin çeviride iki sözcükle ifade edildiği çeviri stratejisidir.

\section{3) Kültürel öğeyi olduğu gibi bırakarak yanına açıklama veya dipnot ekleyerek çevirme}

3.1) Metin içinde açılama vererek çevirme: Kültürel özellik taşıan sözcüğün korunup metin içinde kısa bir açıklama eklenerek ve gerekirse cümle yapısında değişiklik yapılarak çeviri yapma stratejisidir.

3.2) Dipnot vererek çevirme: Kültürel öğeleri açılamak için dipnot kullanma yöntemine başvurulan çeviri stratejisidir.

\section{4) Kültürel öğeyi çevirmeden anlamını veya işlevini açıklayarak çevirme}

Kültürel öğenin tarafsız hale getirilip belirli bir kültüre ait olmaktan çıkarıldı̆̆ı çeviri stratejisidir.

\section{5) Serbest çeviri}

5.1) Erek kültürde bir eşdeğer bularak çevirme: Kaynak metindeki kültürel öğenin erek kültürdeki eşdeğer bir kültürel öğeyle karşılandığı çeviri stratejisidir.

5.2) Deyiş kaydırma yaparak çevirme: Erek metinde eşdeğerlik bulmada zorlanılan durumlarda kullanılabilen bir çeviri stratejisidir. Kültürel öğeyi erek kültüre daha uygun bir kullanımla çevirmek için erek kültürdeki farklı ifade ve atasözlerinden yararlanılarak kaydırma yapılır.

\footnotetext{
Adres $\mid$ Address

İstanbul Medeniyet Üniversitesi, Eğitim Bilimleri Fakültesi, Türkçe İstanbul Medeniyet University, Faculty of Education Sciences, ve Sosyal Bilimler Eğitimi Bölümü, Türkce Eğitimi ABD Cevizli Turkish and Social Scinces Education, Turkish Language Teaching Kampüsü, Kartal-İstanbul/TÜRKIYE $\quad$ Education, Cevizli Campus, Kartal-İstanbul /TURKEY e-posta: editor@rumelide.com 1 e-mail: editor@rumelide.com
} 
6) Silme: Kültürel öğenin çeviri yapılırken silindiği çeviri stratejisidir (Ağıldere ve Yener, 1999).

\section{Karşılaştırmalı inceleme}

\section{1. Çevresel unsurlar}

... sokak çamur deryasına dönmüş.... (s. 72)

... transforming the street into a sea of mud... (s. 8o)

Çevresel unsur niteliğindeki bu kültürel kullanım 1. strateji kullanılarak sözcüğü sözcüğüne çevrilmiştir.

... 'bin tane it'ten geliyor da adı'. (s. 261)

... I picture a pack of dogs... (s. 283)

*Here, Börek Vendor Hasan is indulging in a bit of onomatopoeic word-play: The Turkish pronunciation of Bennett is similar to Bin-İt (Bin: 1000; İt: dog); hence, "A Thousand Dogs" Bennett.

İlk önce it ifadesi 1. strateji kullanılarak sözcüğü sözcüğüne çeviri stratejisine uygun olarak çevrilmiş, daha sonra Türk kültüründe it sözcügüüün taşıdığı yan anlamı belirtmek adına 3.2. stratejiden faydalanılarak dipnot kullanılmıştır.

Karşı koyamaz, şehvetle koşarlardı gencecik canlar bu beyaz gelinin kollarına... (s. 110)

And into her embrace they ran, these young men, by the score, by the thousands (s. 121)

Kaynak metinde çevresel bir unsur olan kar sözcüğü beyaz geline benzetilerek olumlu anlam yüklenerek kullanılmıştır. Erek metinde ise 6. strateji kullanılarak bu unsur silinmiştir.

\section{Maddi kültür}

\section{a. Yiyecek}

... börekler yapip konu komşuya... (s. 15)

... celebratory desserts and börek were sent... (s. 17)

Börek sözcügünün çevirisi yapılmadan, olduğu gibi bırakılmıştır. Metinde ilk geçtiği yer olmasına rağmen açıklamaya veya dipnota yer verilmemiştir. Bu sebeple, seçilen çeviri stratejilerinden herhangi birine uymamaktadır.

...yufka açıyor... (s. 101)

...rolling out $y u f k a^{* * *} \ldots$ (s. 112)

***thin sheet of dough used to make baklava or börek.

Kültürel öğe olduğu gibi bırakılıp dipnot ekleme yoluna gidilerek 3.2. strateji kullanılmıştır.

Düğ̈̈n çorbası, etli pilav, iki değişik zeytinyağlı ve hoşaf yaptırtmıştı. (s. 243)

There was the traditional wedding soup,* rice pilaf with chunks of lamb, two cold vegetable dishes drizzled with olive oil and hoşaf.** (s.263)

\footnotetext{
Adres $\mid$ Address

İstanbul Medeniyet Üniversitesi, Eğitim Bilimleri Fakültesi, Türkçe İstanbul Medeniyet University, Faculty of Education Sciences, ve Sosyal Bilimler Eğitimi Bölümü, Türkce Eğitimi ABD Cevizli $\quad$ Turkish and Social Scinces Education, Turkish Language Teaching Kampüsü, Kartal-İstanbul/TÜRKIYE $\quad$ Education, Cevizli Campus, Kartal-İstanbul /TURKEY e-posta: editor@rumelide.com 1 e-mail: editor@rumelide.com
} 
*Dügün çorbası, a rich stew made with lamb or beef and vegetables.

** hoşaf is a cold drink made with stewed fruit.

Yiyeceklerle ilgili kültürel öğelerin yoğun olarak yer aldığı bu örnekte iki strateji bir arada uygulanmıştır. 1. strateji kullanılarak Düğün çorbası ifadesi sözcüğü sözcüğüne çevrilmiş, daha sonra ise aynı ifadeyi açılamak için 3.2. strateji kullanılarak dipnot eklemiştir. Etli Pilav sözcügü 4. strateji kullanılarak çevrilmiş, Hoşaf sözcüğü ise olduğu gibi bırakılmış ve 3.2. strateji kullanılarak dipnot eklenmiştir.

\section{b. Giyecek}

Ahmet Reşat .... fesini kavukluğa, redingotunu Hüsnü'nün kollarına bırakıp, çoraplarıyla selamlığa girdi. (s. 2)

He grimaced..., removed his shoes, placed his fez on the appointed shelf, handed his redingot ${ }^{*}$ to Hüsnü and entered the selamllk in stocking feet. (s. 2-3)

*derived from French pronunciation of riding coat (redingote); an Ottoman version of a black frock coat.

Fes sözcüğü çevrilirken 1. strateji uygulanmış ve kültürel öğe sözcüğü sözcüğüne çevrilmiş̧tir. Redingot sözcügünde ise 3.2. strateji kullanılmıştır. Birebir çeviri yapıp kültürel bilgi sağlamak adına dipnot kullanılmıştır.

...hemen çarşaflan da... (s. 42)

Get into your çarşaf... (s. 49)

*Çarşaf-an outer garment covering a woman from head to foot.

Bu örnekte 3.2. strateji uygulanarak dipnot kullanılmıştır. Burada çarşaf sözcüğü kitapta ilk kez kullanıldığı için dipnot eklenmiş, sözcük kitabın ilerleyen yerlerinde doğrudan çarşaf olarak çevrilmiştir.

...üzerine temiz bir mintan geçirdi. (s. 280)

He...slipped into a fresh, collarless shirt. (s. 303)

4. Strateji kullanılarak kültürel öğe tarafsız hale getirilmiş ve anlamı çevrilmiştir.

\section{c. Ev ve kasaba}

Sarıkamış macerası hem bedeninde, hem de ruhunda onulmaz yaralar açmıştı. (s. 5)

The disastrous misadventures of Sarıkamış* had left him a broken man, both physically and spiritually. (s. 5)

Kars ilinin bir ilçesi olan ve Türk tarihinde önemli bir yer olan Sarıkamış’ı aktarılırken 3.2. strateji uygulanmış, sözü edilen kişinin psikolojisinin ve davranışlarının, aynı zamanda da eserin geçtiği dönemin koşullarının anlaşılmasında önemli olan bu sözcüğün erek okur tarafından daha kolay anlaşılmasını sağlamak için ise dipnot düşülmüştür.

\footnotetext{
Adres $\mid$ Address

İstanbul Medeniyet Üniversitesi, Eğitim Bilimleri Fakültesi, Türkçe İstanbul Medeniyet University, Faculty of Education Sciences, ve Sosyal Bilimler Eğitimi Bölümü, Türkçe Eğitimi ABD Cevizli Turkish and Social Scinces Education, Turkish Language Teaching Kampüsü, Kartal-İstanbul/TÜRKIYE $\quad$ Education, Cevizli Campus, Kartal-İstanbul /TURKEY e-posta: editor@rumelide.com 1 e-mail: editor@rumelide.com
} 
... İstanbullular... (s. 8)
Residents of İstanbul... (s. 9)

2.2. strateji kullanılarak kaynak metinde tek sözcükle ifade edilen bir öğe erek metinde iki sözcükle ifade etmiştir.

... taşhğa girdi. (s. 45)

...hall... (s. 51)

Burada 4. strateji kullanmıştır. Osmanlı evlerine özel bir bölüm olan taşlık çeviri metinde nötleştirilmiş ve bir kültüre özgülüğü çıkarılmıştır.

\section{d. Ulaşım}

...Kemal'i takanın yalpalaması sersem etti. (s.310)

...as the small sailboat bobbed and dipped Kemal became increasingly sick. (s.335)

Kaynak metinde tek sözcükle ifade edilen kültürel öğe erek metinde iki sözcükle ifade edilmiş ve 2.1. stratejiden faydalanılmıştır.

... sandal gezintileri geldi... (s. 316)

... rowboat excursion... (s. 341)

Bu örnekte 1. strateji kullanılmış ve sözcüğü sözcüğüne çeviri yapılmıştır.

"Oraya bir yayl ile ancak iki günde vasıl olabilmiş". (s. 329)

"He was able to get there only after two days, travelling by horse and cart..." (s. 355)

Her iki örnekte de 4. Strateji kullanılmıştır. Kültürel öğelere çeviride yer verilmemiş, ancak onların anlam ve işlevlerini belirten karşıllklar kullanılmıştır.

\section{Sosyal kültür-iş yaşamı ve boş zaman etkinlikleri}

a. İş

İşgal dönemlerinde arka arkaya sadrazamlık yapan Ali Rıza, Salih Hulusi ve Tevfik paşalar... (s. 9)

Because pashas Ali Riza, Salih Hulusi and Tevfik, the successive holders of the office of grand vizier during the occupation... (s. 10)

Burada, paşa sözcüğü çevrilirken 1. strateji kullanılmıştır. Bu seçimin erek okurda hem yabancılık hem de çeviri hissi verme ihtimali bulunmaktadır. Sadrazamlık sözcüğü ise 5.1. strateji kullanılarak çevrilmiştir. Kaynak metinde tek sözcükle ifade edilen kavram çeviri metinde birden fazla sözcükle ifade edilmiştir.

... sarıklı Hoca... (s. 43)

... turbaned Hodjas... (s. 49)

Bu örnekte 1. strateji kullanılarak sözcüğü sözcüğüne çeviri yapılmıştır.

\footnotetext{
Adres $\mid$ Address

İstanbul Medeniyet Üniversitesi, Eğitim Bilimleri Fakültesi, Türkçe ve Sosyal Bilimler Eğitimi Bölümü, Türkce Eğitimi ABD Cevizli Turkish and Social Scinces Education, Turkish Language Teaching Kampüsü, Kartal-İstanbul/TÜRKIYE $\quad$ Education, Cevizli Campus, Kartal-İstanbul /TURKEY e-posta: editor@rumelide.com 1 e-mail: editor@rumelide.com
} 
... şerbetçiler de gözükmüyordu. (s. 48)

... sellers of refreshing şerbet ${ }^{*} . .$. (s. 55)

*Şerbet in Turkey is a traditional cold drink prepared with rose hips, cornelian cherries, rose or licorice and a variety of spieces, and is believed to have healing effects. It is similar to, but not the same as, sharbat.

2.1. strateji kullanılarak kültürel öğe kısmen korunmuş ve refreshing sözcüğüyle açıklama eklenmiştir. Sonrasında, ayrıntılı bilgi vermek için 3.2. strateji kullanılmış ve dipnot eklenmiştir.

\section{b. Boş zaman etkinlikleri}

... çaldığı uduna ve söylediği İstanbul şarkılarına... (s. 14)

... she played the $u d$ in the evening and and sang Istanbul songs... (s. 16)

Bu kültürel öğe çevrilmeden, kaynak dilde olduğu gibi bırakılmıştır. Bu sebeple, yapılan strateji çalışma başında yapılan sınıflandırmalarından herhangi birine uymamaktadır.

... ablamla gergef işleyeceğime... (s. 90)

... instead of embroiding with my sister... (s. 100)

1. strateji kullanılmıș ve sözcüğü sözcügüne çeviri yapılmıștır.

Bir el pişti veya tavla dahi oynayabilirsiniz. (s.265)

You'll play a game of cards or some backgammon. (s. 287)

Pişti oyunu çevrilirken 4. strateji kullanılmış ve kültürel öğe tarafsız hale getirilerek açılama yapılmıştır. Tavla ise 1. strateji kullanılarak sözcüğü sözcüğüne çevrilmiştir.

\section{Kuruluşlar, gelenekler, faaliyetler, süreçler, kavramlar}

\section{a. Siyasi ve idari}

... zabıta tarafindan... (s. 4)

...by the police... (s. 4)

$\mathrm{Bu}$ örnekte kültürel öğenin erek kültürde bir eşdeğerinin bulunmaması sebebiyle 5.2. strateji kullanılarak deyiş kaydırma yapılmıştır.

... Meclis-i Mebusan'ı basmışlar... (s. 93)

I hear they've forced their way into Parliament... (s. 103)

Burada söz konusu kültürel öğenin kaynak kültürdeki özel konumu göz önünde bulundurulmamış ve 4. Strateji kullanılarak bu öğe tarafsız hale getirilmiş, belirli bir kültüre özgü durumu ortadan kaldırılmıștır.

Önce İttihatçllara taraf olduğu, sonra da onlara sırt çevirdiği için, hem İttihatçlların, hem de karşıtlarının nezdinde sapına kadar suçluydu, kereta. (s.5)

\footnotetext{
Adres $\mid$ Address

İstanbul Medeniyet Üniversitesi, Eğitim Bilimleri Fakültesi, Türkçe İstanbul Medeniyet University, Faculty of Education Sciences, ve Sosyal Bilimler Eğitimi Bölümü, Türkce Eğitimi ABD Cevizli Turkish and Social Scinces Education, Turkish Language Teaching Kampüsü, Kartal-İstanbul/TÜRKIYE $\quad$ Education, Cevizli Campus, Kartal-İstanbul /TURKEY e-posta: editor@rumelide.com 1 e-mail: editor@rumelide.com
} 
Guilty of politically motivated crimes, the scalawag had sided first with the partisans of the Committee of Union and Progress (CUP);* when they were swept to power after the revolution of 1908, he'd turned his back on them, alienating not only CUP supporters but their opponents as well.

*(Turkish: İttihat ve Terakki Cemiyeti) a political party in power from after the revolution of 1908 until 1918, when many of its members were court-martialed and imprisoned. (s. 6)

Bu örnekte adı geçen siyasi kavramın kitabın başlarında yer alması sebebiyle kitabın ileri bölümlerinde geçecek bu siyasi oluşumla ilgili ek bilgi verilmek istenmiştir. Bu sebeple, 2.1. strateji kullanılarak metin içinde, 3.2. strateji kullanılarak da dipnotla ek bilgi verilmiştir. İlerleyen bölümlerde ise kavramı kısaltma yaparak CUP olarak çevrilmiştir.

\section{b. Dini}

"Oğlumuzun adını kulağına siz okuyacaksımı, inşallah," dedi Mehpare. (s. 247)

You'll be the one whispering his name into his ear, God willing," Mehpare said. (s. 267)

Bu örnekte dini bir gelenek olan ezanı bebeğin kulağına okunması çevrilirken ve dini bir ifade olan inşallah ifadesi çevrilirken 1. strateji kullanılmıştır.

...ben rahat rahat helalleşeyim yeğenimle” ... (s.249)

...let me and my nephew make our farewells"* (s.269)

* to make one's farewells in the sense of helalleşmek is much more than simply saying good-bye. It's a ritualistic leave-taking (usually performed on death beds, before battles, or before long separations) in which both parties mutually give or forgive all that has been unjustly taken or done.

Burada hem 4. hem 3.2. stratejiyi kullanılmıştır. Helalleşmek ifadesi ilk önce kültüre özgülüğünden sıyrılıp tarafsız hale getirilmiş, daha sonra dipnot kullanılarak bu öğeyi açıklama yoluna gidilmiştir.

“Kemal Bey’e gitmediğinize dair yemin ediniz ve Kuran’ öpüp başınıza koyunuz o halde.” (s.285)

"Well then, swear on the Koran that you're not going to Kemal Bey." (s.308)

Bu örnekte dini boyuta dayanan bir gelenek çevrilirken 6. strateji kullanılmış ve Kuran’ı öpüp başınıza koyunuz kısmı silinmiştir.

\section{c. Sanatsal}

... sedef kakmah sehpaya... (s. 185)

... on the mother-of-pearl inlaid end table. (s. 202)

1. strateji kullanılarak sözcüğü sözcüğüne çeviri yapılmıştır.

...ebru yapar gibi... (s.368)

...as though...was doing $e b r u^{*}$ (s. 396)

*ebru, or water marbling, is formed by drawing designs with dye on the surface of water and then transferring the whirled image onto paper placed on the water.

\footnotetext{
Adres $\mid$ Address

İstanbul Medeniyet Üniversitesi, Eğitim Bilimleri Fakültesi, Türkçe İstanbul Medeniyet University, Faculty of Education Sciences, ve Sosyal Bilimler Eğitimi Bölümü, Türkce Eğitimi ABD Cevizli Turkish and Social Scinces Education, Turkish Language Teaching Kampüsü, Kartal-İstanbul/TÜRKIYE $\quad$ Education, Cevizli Campus, Kartal-İstanbul /TURKEY e-posta: editor@rumelide.com 1 e-mail: editor@rumelide.com
} 
Türk kültürüne özgü bir sanat dalı olan ebru sanatını çevrilirken 3.2. strateji uygulanarak dipnot kullanılmıştır.

\section{d. Atasözü ve deyimler}

“... körle yatan şaşı kalkar derler...” (s.101)

I believe you are familiar with the expression, "if you lie down with the blind, you will get up crosseyed"?* (s. 112)

*a proverb similar in sentiment to: If you lie with dogs you will get up with fleas.

Bu örnekteki atasözünün eşdeğerini doğrudan metnin içinde kullanmak yerine, ilk önce 1. strateji kullanılarak sözcüğü sözcüğüne çeviri yapılmış, daha sonra ise 3.2. strateji kullanılarak dipnotla eşdeğer bir atasözüne yer verilmiştir.

Kendi kendine gelin güvey olup başını belaya sokmaya gidiyorsun. (s.249)

You're asking for trouble, the two of you, husband and wife. (s. 269)

Bu örnekte 6. strateji kullanılarak gelin güvey olmak deyimi silinmiştir.

“Ağzım sıkıdır benim.” (s.287)

"My lips are sealed". (s. 310)

Burada 5.1. stratejiyi kullanılmış ve kültürel öğenin erek kültürdeki bir eşdeğerine yer verilmiştir.

\section{Jestler ve alışkanlıklar}

... ağır yüklerinin altında iki büklüm olmuş birkaç hamal, yere bağdaş kurmuş dilenciler... (s. 43)

... street porters bent double under their towering loads, beggars sitting cross-legged on the sidewalk... (s. 49)

İki büklüm olmak ifadesinin çevirisi için 4. strateji kullanılmış ve kültürel öğenin kendisi değil anlamı çevrilmiştir. Bağdaş kurmak ifadesi ise 1.strateji kullanılarak sözcüğü sözcüğüne çevrilmiştir.

"Horozlanma o zaman” ... (s. 264)

“Then stop strutting about” ... (s. 286)

1. strateji kullanılmış ve sözcüğü sözcüğüne çeviri yapılmıştır.

“Keh keh güldü” ... (s. 320)

... chuckled Captain Mustafa”... (s. 345)

Günlük dilde kullanılan bu ifade 5.1. strateji kullanılarak eşdeğer bir ifadeyle çevrilmiştir.

\section{Sonuç}

Kültürel öğelerin çevirisi iki farklı dil ve kültür dizgesinin söz konusu olması sebebiyle özellikle de kültürel öğelerin yoğun olduğu metinlerde çevirmenler için zorluk çikarmaktadır. Ayşe Kulin gibi eserlerinde kültürel öğelere yoğun bir şekilde yer veren yazarların eserlerini çevirmek de bu sebeple çok daha zordur. Ancak, zorluğunun yanında bir kültürün başka bir kültürde tanıtılması ve bir

\footnotetext{
Adres $\mid$ Address

İstanbul Medeniyet Üniversitesi, Eğitim Bilimleri Fakültesi, Türkçe İstanbul Medeniyet University, Faculty of Education Sciences,

ve Sosyal Bilimler Eğitimi Bölümü, Türkce Eğitimi ABD Cevizli Turkish and Social Scinces Education, Turkish Language Teaching

Kampüsü, Kartal-İstanbul/TÜRKIYE Education, Cevizli Campus, Kartal-İstanbul /TURKEY

e-posta: editor@rumelide.com $\quad \begin{aligned} & \text { e-mail: editor@rumelide.com } \\ & \text { e-com }\end{aligned}$
} 
ülkedeki edebiyatseverlere bir başka ülkenin edebiyatından eserler sunulup bu edebiyatın tanıtılması açısından da bu tür metinlerin çevirileri oldukça önem taşımaktadır.

Çevirmenler de bu sorumluluğu yerine getirirken kültürel öğeleri çevirmenin zorluklarıyla başa çıkmak için çok çeşitli stratejilere başvurmaktadırlar. Bu stratejileri seçerken çevirinin erek kültürde çok yabancı durması ve anlaşılamaması tehlikesiyle veya kaynak kültürün tamamen yok olup metnin erek dilde yazılmış bir esermiş gibi görünmesi tehlikesiyle karşılaşmaktadırlar. Bu sebeple, kaynak ve erek metin arasındaki dengeyi kurmak zorundadırlar.

$\mathrm{Bu}$ çalışmanın sonucu olarak, çevirmenin kültürel öğelerin çevirisinde farklı stratejileri bir arada kullandığı söylenebilir. Çevirmenin kullandığı stratejiler ise sıklğına göre şu şekilde sıralanabilir: 1 . Strateji (13 kez); 3.2. Strateji (12 kez); 4. Strateji (8 kez); 2.1., 5.1. ve 6. Strateji (her biri 3 kez); 2.2. ve 5.2. strateji (her biri 1 kez). Çevirmen 3.1. stratejiden faydalanmamıştır. Ayrıca, çevirmenin önceden saptanan stratejiler arasında bulunmayan bir stratejiden daha faydalandığı tespit edilmiştir. Çevirmen iki kültürel öğenin çevirisinde kaynak kültürdeki öğeyi çevirmeden, olduğu gibi bırakmayı tercih etmiştir. Bunların yanında, zaman zaman aynı kültürel öğe için birden fazla stratejiden faydalanmıştır. Seçilen kültürel öğelerin çevirisinde kullanılan çeviri stratejilerinin slklığı göz önünde bulundurulduğunda, çevirmenin ağırlıklı olarak birebir çevirmeyi tercih ettiğini, bunun mümkün olmadığı veya uygun düşmediği durumlarda ise dipnot eklemeyi uygun gördüğünü söylemek mümkündür. Çevirmen, dipnot ekleyerek erek kültür okuyucusunu söz konusu kültürel öğe hakkında bilgilendirmeyi amaçlamıştır. Bunlara ek olarak, kullanılan çeviri stratejilerinin de hangi kültürel öğenin çevrildiğine, o öğenin erek kültüre yakınlığına ve kitabın hangi bölümünde (baş-orta-son) geçtiğine göre değişiklik gösterdiği söylenebilir.

Çevirmenin bu çabası göz önünde bulundurulduğunda, çevirmenlerin sadece iki dili değil, aynı zamanda iki kültürü de bilmesinin önemi gözler önüne serilmektedir. Ancak her iki dili ve kültürü iyi derecede bilen bir çevirmen çeviri sürecini hakkıyla yürütebilir. Bu çalışma, özellikle birbirine uzak iki dil ve kültürün seçilmesi sebebiyle kültür öğelerinin çevrilmesinin ne kadar zor olduğunu bir kez daha ortaya koymuştur. Diğer yandan, söz konusu çevirinin çeviri stratejilerini doğru yerlerde kullanan bir çevirmenin de bu zorlukla baş edebileceğini, kaynak dilden aldığı ifadeyi erek dil ve kültüre aktarabileceğini gösterdiği görülmüştür. Türkçeden İngilizceye yapılan çeviri incelemelerine İngilizceden Türkçeye yapılan çeviri incelemelerinden daha az ağırlık verildiği düşünüldüğünde, bu anlamda da bu yöndeki çeviriler için fikir verici olması hedeflenmiştir.

Tüm bunlar göz önünde bulundurulduğunda, Kenneth J. Dakan'ın Ayşe Kulin’in Veda: Esir Şehirde Bir Konak romanının çevirisiyle, İngilizce okuyan erek kültürün Türk kültürüyle ilgili birçok kültürel öğeden haberdar olmasını sağladığı ve kaynak kültürdeki etkiyi erek kültüre aktarımıyla bir Türk yazarın yurtdışında tanıtılmasını ve okunmasını sağladığını söylemek yanlış olmayacaktır.

\section{Kaynakça}

Ağlldere, S. ve Yener, Ş. (1999). The Problem of Translation of Cultural Features into English and French in Yaşar Kemal'sWork, Ortadirek, The wind the Plain and Piller, $1^{\text {st }}$ International Conference. Hacettepe: Cultural Encounters and Cultural Differences, Ankara.

Bassnett-McGuire, S. (1980). Translation Studies. Londra: Richard Clay Ltd. Press.

Dizdar, D. (2004). Hans J. Vermeerle Söyleşi. Varlık, 1155, 30-33.

Ece, A. (2016). Çevirmenin Yazar ve Kahraman Olarak Portresi. İstanbul: Çeviribilim Yayınları.

Göktürk, A. (2004). Çeviri Dillerin Dili. İstanbul: Yapı Kredi Yayınları.

\footnotetext{
Adres $\mid$ Address

İstanbul Medeniyet Üniversitesi, Eğitim Bilimleri Fakültesi, Türkçe İstanbul Medeniyet University, Faculty of Education Sciences, ve Sosyal Bilimler Eğitimi Bölümü, Türkce Eğitimi ABD Cevizli Turkish and Social Scinces Education, Turkish Language Teaching Kampüsü, Kartal-İstanbul/TÜRKIYE $\quad$ Education, Cevizli Campus, Kartal-İstanbul /TURKEY e-posta: editor@rumelide.com 1 e-mail: editor@rumelide.com
} 
Gürçă̆lar, T., Ş. (2011). Çevirinin ABC’si, Say Yayınları, İstanbul.

Katan, D. (2009). Culture. Mona Baker ve Gabriela Saldanha (editörler). Encyclopedia of Translation Studies. 2. bs (ed.). Londra ve New York: Routledge, 70.

Köksal, D. (2008). Çeviri Ĕ̆itimi, Kuram ve Uygulama. Ankara: Nobel Yayın Dağıtım.

Kulin, A. (2007). Veda: Esir Şehirde Bir Konak. İstanbul: Everest Yayınları.

Kulin, A. (2008). Farewell: A Mansion in Occupied İstanbul. İstanbul: Everest Yayınları.

Newmark, P. (1988). A Textbook of Translation, New York: Prentice Hall.

Nida, E.A. (1993). Language, Culture and Translation. Şanghay: Shanghai Foreign Language Education Press.

Öztemel-Akbay F., Metin-Tekin B. (2018). J.M. Barrıes in Peter Pan Adlı Eserindeki Özel İsimler ve Çeviri Stratejileri Üzerine Karşlaştırmalı Bir İnceleme. The Journal of International Social Research, 11 (55), 175.

Ayşe Kulin kimdir? (2015). 16 Nisan 2015 tarihinde http://www.hakkindakisabilgi.net/ayse-kulinkimdir.html adresinden alınmıştır.

Dakan, Kenneth (2015). 16 Nisan 2015 tarihinde http://www.worldcat.org/identities/lccnno2008162483/ adresinden alınmıştır.

(2015). 18 Nisan 2015 tarihinde www.tdk.gov.tr adresinden alınmıştır. 